\title{
“OTRAS SALIDAS”. ALTERNATIVAS DE LOS MIEMBROS LEALES FRENTE AL DETERIORO DE LAS NUEVAS REALIDADES CARISMÁTICAS
}

"Other exits": alternatives for faithful members in the face of the decline of new charismatic realities

Juan Bautista Duhau

\section{Resumen}

La dimensión carismática de la Iglesia se compone de todas las asociaciones tradicionales, caracterizadas por fines particulares, así como también de los Institutos de Vida Consagrada y de las Sociedades de Vida Apostólica, y de las agregaciones de fieles más recientes como los movimientos eclesiales, las nuevas comunidades y las nuevas formas de vida consagrada. Estas organizaciones que componen la dimensión carismática de la Iglesia atraviesan crisis de deterioro y declive; esto acontece actualmente en las nuevas realidades, surgidas tanto antes como después del Concilio Vaticano II. Todas las organizaciones eclesiales de naturaleza carismática son organizaciones motivadas por ideales donde el deterioro institucional que menoscaba las motivaciones profundas es muy nocivo. Las nuevas realidades carismáticas recorren actualmente un momento crítico en su evolución. Algunos grupos viven crisis de crecimiento, de adaptación o actualización, atraviesan etapas de rutinización del carisma; otros transcurren momentos de recambio generacional en el liderazgo; y otras organizaciones sufren el impacto de las denuncias de abusos cometidos por fundadores, líderes carismáticos o figuras notables en la generación fundacional. En este artículo nos proponemos analizar el comportamiento de los miembros insatisfechos frente al deterioro de estas organizaciones motivadas por ideales a partir de las reflexiones del economista Albert Hirschmann. Se trata de un ejercicio de discernimiento que busca aportar elementos de reflexión y horizontes de renovación y actualización en las organizaciones carismáticas.

1 Doctor en Teología por la Pontificia Universidad Católica Argentina (2019). Profesor en el Centro de Estudios Filosóficos y Teológicos (CEFYT), Córdoba, Argentina. Miembro de la Sociedad Argentina de Teología (SAT). Correo electrónico: jbduhau@outlook.com.ar 
Palabras clave: Movimiento religioso; Comunidad religiosa; Cambio organizacional; Organizaciones motivadas por ideales; Nuevas realidades carismáticas.

\section{Abstract}

Charismatic dimension of the Church is determined by traditional associations, Institutes of Consecrated Life and Societies of Apostolic Life, as well as by the most recent congregations of believers such as ecclesial movements, new communities, and new possibilities for consecrated life. These organizations are suffering a decline, which occurs within new realities that emerged both before and after Second Vatican Council. All ecclesial organizations of charismatic nature are based on ideals in which the institutional deterioration that damage deep motivations turns out to be quite harmful. New charismatic realities are undergoing a critical moment in their evolution: Some groups experience growth, adaptation or updating issues; some undergo times of routinization of charisma; some go through generational changes; and some other suffer the impact caused by complaints of abuses committed by founders, charismatic leaders, or prominent figures. Based on the views of the economist Albert Hirschman, the purpose of the article is to analyze the behavior of dissatisfied members in the face of the decline of these value-based organizations. It is an exercise that aims at contributing ideas and horizons for renewal and update within charismatic movements.

Keywords: Religious Movements; Religious Communities; Organizational Change; Values-Based Organizations; New Charismatic Realities.

\section{Introducción}

La dimensión carismática en la Iglesia reúne las tradicionales formas de vida religiosa, como Congregaciones, Institutos y Sociedades de Vida Apostólica, y desde los años posconciliares una gran variedad de nuevas formas asociativas como los movimientos eclesiales, las nuevas comunidades y las nuevas formas de vida consagrada. Las realidades eclesiales de naturaleza carismática son organizaciones motivadas por ideales que, por atravesar experiencias de deterioro institucional, sufren la pérdida de miembros valiosos.

El declive y deterioro de las organizaciones es una preocupación en la dimensión carismática, de difícil explicación por su multicausalidad. En este artículo nos proponemos establecer un diálogo entre los análisis realizados por Albert Hirschmann (1977) al estudiar la declinación en empresas y organismos, el magisterio eclesial y las reflexiones institucionales de la vida consagrada.

En ese encuentro de diversos discursos presentamos los caminos que recorren los miembros de las instituciones frente al deterioro institucional. Articulando el análisis realizado, desde perspectivas económicas y políticas con la realidad de las organizaciones motivadas por ideales, buscamos comprender las dinámicas de reclamo y protesta de los miembros leales de una organización que hacen uso de su voz por sobre la posibilidad de la salida en las realidades carismáticas de la Iglesia. 
El artículo presenta la realidad de la dimensión carismática en la Iglesia y se describen especialmente las nuevas comunidades surgidas en ella. Plantearemos las dinámicas de desgaste y deterioro dentro de las organizaciones carismáticas y cómo afectan a sus integrantes, para luego señalar las opciones de los miembros insatisfechos frente a la falta de salud organizacional. A continuación, plantearemos el modo en que el apego o lealtad de los miembros a una institución moldea las opciones de la voz o de la salida en las organizaciones y cómo las prácticas institucionales pueden hacer muy costoso expresar la queja o plantear la salida. Finalizaremos con algunas conclusiones que abran un horizonte de esperanza al escenario planteado.

\section{La dimensión carismática en la Iglesia}

El Espíritu Santo derrama dones salvíficos extraordinarios, genera la unidad de la Iglesia en la comunión y en el servicio, y provee de numerosos dones jerárquicos y carismáticos vivificando las instituciones eclesiásticas (cf. AG 4) (Schilier, 1979). Habitando la Iglesia y el corazón de los hombres, guía la Iglesia y es fuente de unidad y comunión de los dones que la componen (cf. LG 4).

Uno de los rasgos particulares de la mirada sobre la Iglesia ofrecido por el Concilio ha sido acentuar la acción del Espíritu Santo en la comunidad eclesial, atribuyéndole una función de animación del cuerpo eclesial y señalando que él es quien infunde vida a las estructuras de salvación que Cristo ha instituido (Meis-Wörmer, 2009). La Iglesia no es una estructura anquilosada, sino que -gracias a la acción vivificadora del Espíritu que anima y moviliza a los creyentes- es realmente una organización, pero una organización viva y vivificadora, es decir, un cuerpo vivo, un organismo eclesial (Polanco, 2003a).

Esta reflexión sistemática, que funda una sana pneumatología -fuente de toda eclesiología-, restituyó en la Iglesia una conciencia de la acción carismática habitual del Espíritu Santo en la comunidad eclesial y clarificó que esta acción del Espíritu Santo no sólo se realiza mediante los sacramentos y las virtudes, sino que existe un modo distinto, sumativo, de su acción por medio de gracias especiales: los dones o carismas que se distribuyen en fieles de cualquier condición (Polanco, 2003b). Estas se distinguen de las gracias concedidas universalmente por medio de los sacramentos y los ministerios de santificación, dirección o gobierno; conceden a los fieles aptitudes que los hacen diligentes al realizar las obras y necesidades que presenta la Iglesia especialmente para construirla y rejuvenecerla.

A partir de la renovación propuesta por el Concilio Vaticano II, la comunidad cristiana no sólo es la Iglesia de la jerarquía y los sacramentos sino también la Iglesia de los carismas (Madrigal Terrazas, 2006). El Espíritu unifica la Iglesia «en comunión y ministerio» (LG 4), reuniendo las dimensiones carismática e institucional, reflejando así la unidad y complementariedad de la dimensión cristológica y pneumatológica del misterio de la Iglesia (Gerosa, 1988; Oviedo Cavada, 1984; Villar, 1998).

Los institutos religiosos no forman parte de la estructura jerárquica, pero pertenecen a su vida y santidad (LG 44) (Hortal, 1971), conformando la dimensión carismática de la Iglesia en la que conviven las organizaciones de la vida consagrada (Codina, 1994). Una mejor comprensión de la relación existente entre los dones jerárquicos y carismáticos derramados en la Iglesia se alcanza con la recepción de los documentos del Concilio Vaticano II (Ker, 2002; Santos Díez, 1967). La teología sobre los carismas, 
desplegada a partir de las enseñanzas del Vaticano II (cf. LG 12), permitió describir la misión esencial de la vida religiosa y caracterizar así esta dimensión carismática de la Iglesia (Rambaldi, 1975).²

La Vida Consagrada ha prosperado en medio de muchas culturas y a través de todos los períodos de la historia, su presencia es universal en las confesiones cristianas, principalmente en la Iglesia Católica y en las Iglesias Ortodoxas. La inicial "sequela Christi" de los primeros cristianos encontró continuidad en el gran movimiento eremítico, en los fundadores de los monasterios (San Basilio y San Benito), más tarde en la adaptación de la vida consagrada a variados servicios ofrecidos a la Iglesia por los hermanos franciscanos y dominicos, los jesuitas y las modernas congregaciones (Conner, 1999).

La dimensión carismática de la Iglesia se origina por el surgimiento de una gran diversidad de Institutos religiosos, dando al dinamismo pneumatológico concreción y variedad histórica (Otaduy Guerín, 2018). Cada familia religiosa que surge es un proyecto existencial derivado del modelo ofrecido por el fundador/a y un don del espíritu para la Iglesia (Vigano, 1985).

Una de las características de los años postconciliares fue la difusión de nuevas formas agregativas de fieles, con una gran variedad en sus fisonomías y finalidades las cuales incluyen los nuevos movimientos eclesiales, las nuevas comunidades y nuevas formas de vida consagrada (Leonard, 2001). Estas recientes realidades son fenómenos asociativos propios de la dimensión carismática, donde se encuentran ya desde antiguo las organizaciones que nuclean la vida religiosa en la Iglesia (Rambaldi, 1987).

Estos nuevos grupos fueron reconocidos por Juan Pablo II como fenómenos asociativos propios de la dimensión carismática, que es parte constitutiva de la esencia de la Iglesia, ubicando estas organizaciones en el marco de los carismas que fecundan la comunidad eclesial (Delgado Galindo, 2010).

Las nuevas realidades asociativas carismáticas incluyen mayoritariamente a laicos y crean un compromiso existencial en vista de la realización de la vocación cristiana (Ratzinger, 1999). Tal como ocurrió en la historia de la Iglesia con las congregaciones religiosas u otras instituciones carismáticas, los movimientos y nuevas comunidades tienen su origen casi siempre en un fundador/a, y se forjan en comunidades que al nutrirse del carisma surgido proponen nuevas formas de vivir el Evangelio en el seno de la comunidad eclesial (Delgado Galindo, 2013).

Los nuevos movimientos eclesiales y las nuevas comunidades presentan aspectos novedosos: reúnen miembros de todos los estados de vida; en ocasiones el «carisma de fundador» es recibido por fieles laicos y el «carisma fundacional»se extiende mayoritariamente entre los seglares. En este sentido, los laicos no se suman a compartir un patrimonio madurado desde la vida religiosa y sacerdotal, como sucede en las terceras órdenes (Areitio, 2010), sino que forman parte de la fundación y el crecimiento de una nueva familia

2 Al discutirse el esquema De Ecclesia en el Concilio Vaticano II, el Card. Suenens, realizó una intervención sobre la dimensión carismática de la Iglesia y acercó una reflexión considerando la estructura jerárquica de la Iglesia en una íntima conexión con los dones carismáticos del Espíritu Santo. Este aporte fue volcado en el texto del parágrafo 12 de Lumen Gentium y se convirtió en el fundamento de la reflexión sobre la dimensión carismática de la estructura de la Iglesia (Madrigal Terrazas, 2015). 
espiritual, que incluirá religiosas, religiosos y presbíteros, pero con un pie de igualdad en la experiencia del surgimiento del nuevo carisma en la Iglesia.

Todas estas realidades asociativas carismáticas pueden ser consideradas en conjunto, pues tienen en común su origen en un fuerte carisma que las origina y les da identidad. Se trata de una "galaxia» de organizaciones, asociaciones y grupos de lo más diversas que conforman el conglomerado de las «nuevas realidades eclesiales» (Faggioli \& Yocum, 2014) y que optamos por denominar «nuevas organizaciones carismáticas». Estas nuevas realidades presentan una gran variedad y complejidad tanto internamente como en términos de diferentes áreas geográficas, con respecto a su lugar y fecha de nacimiento, tipo de membresía, tamaño y arraigo, misión dentro de la Iglesia y orientación teológica (Duhau, 2019).

La pluralidad de expresiones en esta galaxia de nuevas realidades carismáticas es obstáculo para definir claramente el fenómeno de los movimientos eclesiales surgidos en derredor del Concilio Vaticano II: "de este modo podemos hablar de "asociaciones, grupos, comunidad y movimientos» (ChL 29); «nuevas formas de vida evangélica, nuevas Fundaciones» (VC 62); «los nuevos protagonistas: movimientos, asociaciones, grupos»; «movimientos eclesiales»; «communautés nouvelles»" (Etxeberría, 2019, p. 7).

La reciente Carta Iuvenescit Ecclesia (a cont. IE) de la Congregación para la Doctrina de la Fe (2016), las denomina "grupos eclesiales" en una categoría general y abarcativa, para luego nombrarlas más particularmente como "agregaciones de fieles", "movimientos eclesiales" y "nuevas comunidades"; y agregando el adjetivo "multiformes» para indicar que pueden expresarse en diferentes estados de vida: fieles laicos, presbíteros y miembros de la vida consagrada (cf. IE 2) (Martinelli, 2017). Al describirlas señala que estas realidades son más recientes sin dar cuenta temporalmente de lo que esto puede significar cronológicamente e indica que se suman al valor y riqueza que ya suponían en la Iglesia "todas las asociaciones tradicionales, caracterizadas por fines particulares, así como también los Institutos de Vida Consagrada" (IE 2). Son realidades fuertemente dinámicas, de allí el haber sido caracterizadas como «movimientos», que no pueden ser reducidas a un mero asociacionismo tras un objetivo particular, sino que derivan de un carisma compartido con el fin apostólico de todos los miembros de la Iglesia (Abignente, 2018).

Leidi (2014) habla de «nuevos carismas» indicando que puede tratarse de: a) Institutos que ya han recibido una aprobación como institutos seculares o bajo otras formas jurídicas: Notre-Dame de Vie, Schönstatt o el Opus Dei; b) grupos sin vida común o movimientos eclesiales que dejan a sus miembros una plena libertad en las opciones de vida (celibato o matrimonio) y de profesión: la Acción Católica, Comunión y Liberación, el Camino neocatecumenal, los Cursillos de Cristiandad (Matas Pastor, 2000), la Obra de María-Movimiento de los Focolares; o c) grupos o fundaciones que viven el celibato (prometido con votos u otros vínculos sagrados), adoptan en todo o en parte la vida común, practican el compartir los bienes, se someten internamente al régimen de responsables libremente elegidos en especiales asambleas, viven de forma autónoma como comunidades de consagrados o como consagrados asociados a algún movimiento, con formas de participación que varían desde la asociación a la integración de pleno derecho en el grupo denominados nuevas o renovadas formas de vida consagrada, nuevas comunidades o asociaciones de vida evangélica a las que se refiere la Exhortación Apostólica Vita Consecrata 12 y 62 (a cont. VC).

Una de las cuestiones problemáticas que surgen alrededor de estas nuevas realidades carismáticas es su integración en las Iglesias locales, ya que al ser ésta la última oleada carismática que ha surcado la estructura 
fundamental y permanente de la Iglesia a través de los tiempos, es normal entonces que sea quien haga surgir nuevamente la discusión sobre la relación adecuada entre la institución y los carismas (Cattaneo, 1998).

Esta tensión en la relación entre carisma e institución, producida por la novedad de estos nuevos carismas se da a la hora de reconocer jurídicamente estas realidades agregativas: "La tarea es sumamente delicada porque por una parte se ha de evitar que se asfixie el carisma y por otra se ha de favorecer su inserción en la comunión de la Iglesia" (Navarro, 2018, p. 216).

Iuvenescit Ecclesia enumera las formas jurídicas para el reconocimiento de las realidades de naturaleza carismática en la Iglesia: las Asociaciones privadas y públicas de fieles (Delgado Galindo, 2010), las Asociaciones de fieles clericales, los Institutos de vida consagrada, las Sociedades de Vida apostólica (Bahíllo Ruiz, 2016) y las Prelaturas Personales (Amadeo Fuenmayor, 1983; Amadeo Fuenmayor \& Rodríguez García, 1984; Miras, 1999; Viana, 1997, 2008, 2012).

De algunos nuevos movimientos, por una estrecha vinculación entre sus integrantes consagrados y los miembros laicos, han surgido «nuevas formas de vida consagrada» (González Ayesta, 2009). Se trata de nuevas comunidades con tradiciones religiosas algunas de tipo monástico (Keenan, 2002; Howard, 2019), plurivocacionales, que además pueden ser ecuménicas y/o extenderse internacionalmente (Bamberg, 2009).

Otro aspecto de estas nuevas agrupaciones de fieles que presenta interesantes desafíos es la inserción en ellas de múltiples realidades vocacionales: sacerdotes, religiosos y religiosas, laicos y laicas consagradas, matrimonios y familias.

En relación con los sacerdotes se dan dos situaciones fundamentales; por una parte, clérigos que, al entrar en contacto con la nueva comunidad, permanecen incardinados en su diócesis participando de la espiritualidad y las actividades del movimiento, o aquellos que abrevando en esta nueva experiencia espiritual se forman como sacerdotes diocesanos y permanecen vinculados con la organización carismática; por otra parte, sacerdotes que experimentan su vocación ministerial como un llamado que surge desde la experiencia de la nueva comunidad para servir a los fieles de esa realidad (Ker, 2005; Navarro, 2008; Rodríguez García, 1970).

Algo similar ocurre al vincularse un miembro de un instituto religioso con un movimiento eclesial, ya porque se acercan a los institutos religiosos vocaciones provenientes de la experiencia carismática de una nueva comunidad, ya porque un religioso experimenta que la espiritualidad de un movimiento alimenta y potencia su vocación consagrada (González Ayesta, 2009). El modo de vinculación es muy variable de acuerdo con el modo de organizarse de cada organización carismática, desde una vinculación ocasional con la espiritualidad surgida en la nueva comunidad a un compromiso constante con las actividades del movimiento (Areitio, 2010).

Por otro lado, las nuevas formas de vida consagrada incluyen, dentro de su estructura, a miembros laicos casados que expresan un compromiso estable en esa realidad eclesial. Dado que es claro que los matrimonios no forman parte de la vida consagrada, pero que sí pueden realizar voto de castidad, según su propio estado de vida, su inserción en una organización carismática de vida consagrada representa aún una búsqueda en la reflexión teológica y canónica (Areitio, 2010). 


\section{Un nuevo momento para las nuevas realidades carismáticas}

Para ensayar una reflexión sobre el deterioro en las organizaciones, asumimos como un conjunto heterogéneo las nuevas formas de vida consagrada, los movimientos eclesiales y nuevas comunidades.

Todas estas organizaciones eclesiales de naturaleza carismática -tanto las antiguas como las más recientes- son, en definitiva, «organizaciones motivadas por ideales (OMI)» (Bruni \& Smerilli, 2009), ${ }^{3}$ donde "las motivaciones de las personas son el factor decisivo y la vida organizativa entera" (Bruni, 2017, p. 18). La vida de estas realidades, nutridas por ideales y pasiones, tiene una necesidad esencial de motivaciones intrínsecas y profundas; en ellas el deterioro institucional que produce la pérdida de las motivaciones más profundas, creadoras y libres es fatal (Bruni, 2017, p. 42).

Las nuevas realidades carismáticas atraviesan actualmente un momento crítico en su evolución, luego de un primer y espontáneo nacimiento y su posterior bullicioso crecimiento. Esta «tercera fase», en palabras de Piero Coda (2018), es casi sucesiva a la conclusión del período fundacional, y se vuelve una oportunidad para lograr una equilibrada institucionalidad que permita la mejor contribución del propio carisma a las necesidades de la evangelización.

Esta tercera etapa se caracteriza por la experiencia de las crisis ad-intra de las nuevas realidades eclesiales.

Algunos grupos eclesiales atraviesan crisis de crecimiento, necesitados de una adaptación o actualización. Se trata muchas veces de verdaderas etapas de rutinización del carisma, de la transformación del ideal carismático en una organización institucional con continuidad histórica (Eisenstadt, 1973; Schoon \& West, 2017). Además, varios de estos grupos eclesiales atraviesan un recambio generacional en los niveles de liderazgo y conducción (Bunton, 2019), que supone una nueva consideración sobre diversidad de temas: el carisma originario y la posibilidad de su revisión, actualización o reforma; el rol del fundador/a o de la generación fundacional; la misión de los miembros activos de las nuevas organizaciones carismáticas como intérpretes válidos del carisma recibido; las dinámicas de institucionalización en las nuevas formas carismáticas, etc.

Otras organizaciones han entrado en crisis debido al develamiento de las faltas graves cometidas por fundadores o miembros relevantes de la organización (Faggioli, 2019). El impacto de las denuncias de abusos cometidos por fundadores, líderes carismáticos o figuras notables en la generación fundacional causó una verdadera conmoción en las nuevas realidades carismáticas (Zollner, 2018). "Existen «otros» Marcial Maciel” (Beltramo Álvarez, 2014) señaló explícitamente el cardenal Joao Braz de Aviz, indicando que existe más de un fundador de congregaciones, institutos religiosos y movimientos que no vivieron o no viven de acuerdo con la propuesta que han ofrecido a sus seguidores.

Se han abierto así crisis multicausales en las nuevas organizaciones carismáticas, que muchas veces se expresan como frustración o decepción del proyecto vocacional tanto laical, consagrado o presbiteral

3 Estos términos traducen la expresión en inglés «Values-based Organizations» (VBOs); también estas organizaciones son denominadas «values-driven organizations» and «ideological organizations». (Bruni \& Smerilli, 2009, p. 272) 
en una realidad carismática, y que en muchas oportunidades motiva la salida y, el abandono se presenta como la única vía para no sucumbir (CIVCSVA, 2017).

\section{El deterioro de las realidades carismáticas y de las organizaciones motivadas por ideales}

Cualquier organización está sujeta a fallas en su comportamiento virtuoso o funcional. Para evitar que el mal funcionamiento se retroalimente, o conduzca a un decaimiento general, es necesario que se reúnan fuerzas dentro de la organización que hagan volver al mayor número posible de miembros al buen funcionamiento (Hirschman, 1977).

El análisis realizado por A. Hirschmann (1915-2012) en su obra Salida, voz y lealtad. Respuestas al deterioro de empresas, organizaciones y estados, sobre los momentos de deterioro de las organizaciones se nos presenta como una alternativa válida para pensar en un primer paso, las dinámicas de desgaste y desmejora de las realidades carismáticas, y en un segundo paso cómo estas dinámicas contribuyen al abandono de los miembros de estas organizaciones. ${ }^{4}$

La declinación o deterioro puede deberse tanto a múltiples causales ad-intra de la organización factores subjetivos que operan al azar y son reversibles-, como a cambios ad-extra de la realidad carismática, debido a variables adversas en el contexto cultural y social que afectan al buen funcionamiento.

Las causas del deterioro hacia dentro de las organizaciones carismáticas son múltiples. En las organizaciones más tradicionales, como las congregaciones religiosas -especialmente femeninas-, el desafío de la multiculturalidad ha provocado fuertes tensiones al iniciar obras en nuevos contextos geográficos o multi-religiosos. En otras realidades se reconoce una incapacidad para dejar de administrar situaciones bien conocidas y pasar a conducir la comunidad hacia metas e ideales con verdadera confianza; por lo que frente a las situaciones de cambio se vive apagando incendios en la gestión continua de emergencias sin una real posibilidad de imaginar recorridos para una sana evolución de la institución carismática (CIVCSVA, 2017).

Luigino Bruni plantea el deterioro de una organización carismática con la imagen de una «enfermedad autoinmune» enraizada en el "mal manejo del miedo a perder la originalidad y la identidad específicas del «carisma» del fundador" (Bruni, 2017, p. 56). Esta dolencia de las organizaciones y comunidades crea anticuerpos para protegerse de la innovación, comportamiento que en lugar de defenderlas las destruye y, paradójicamente, este camino se inicia al alcanzar el máximo éxito y crecimiento. Es la dinámica del «comienzo del atardecer en pleno mediodía» donde se construyen estructuras jerárquicas que orientan todas las actividades a potenciar los aspectos exitosos de la organización (Bruni, 2017, p. 66).

4 Hischmann indica que su planteo se origina al estudiar empresas que producen bienes para su comercialización, también señala que, en gran medida y en ocasiones muy pertinentemente, es aplicable a organizaciones como asociaciones de voluntariado o partidos políticos, que ofrecen servicios a sus miembros. En el recorrido de nuestra reflexión hemos seleccionado aquellos elementos de análisis que pueden ser aplicados a las nuevas comunidades de la dimensión carismática en la Iglesia. 
Como toda enfermedad presenta síntomas: la incapacidad general para atraer nuevas personas, creativas y de calidad y la falta de eros, pasión y deseo que se manifiesta en una apatía organizativa colectiva.

¿Cómo se llega a esta situación de falta de salud? Bruni indica algunos comportamientos que son verdaderas "trampas de pobreza que se autoalimentan" (Bruni, 2017, p. 60). Presentamos algunos: a) la reducción del carisma a ideología transformándolo en la explicación de todas las realidades, separándolo del contexto en que surge e impidiendo que sea puesto en discusión y purificado por realidades distintas y más universales; b) la dificultad para integrar una «confianza vulnerable» capaz de fortalecer la organización, dado que la capacidad de engendrar creativamente vida nueva está relacionada, irremediablemente, con relaciones humanas en las que, por la confianza ofrecida, pongo al otro en la posibilidad de «herirme»; c) la tendencia a suplantar las motivaciones intrínsecas de los miembros «leales» por incentivos y controles, que se vuelve fatal para las organizaciones que se nutren de ideales y carismas.

Frente a estos comportamientos que conducen a un decaimiento general en las organizaciones carismáticas es necesario proponer mecanismos de recuperación, que permitan evitar sufrimientos humanos y pérdidas sociales y hagan volver al mayor número posible de miembros al buen funcionamiento (Hirschman, 1977). Es un ejercicio imprescindible de discernimiento para comprender la problemática actual de estas organizaciones, que debe hacerse con respeto y modestia frente al misterio de vida que son las distintas realidades carismáticas surgidas en la Iglesia por obra de la riqueza del Espíritu de Dios (Theobald, 2016).

\section{Salir o expresarse: opciones de los miembros insatisfechos frente al deterioro de las organizaciones carismáticas}

Si la única vía de salida que surge frente a las situaciones frustrantes en las comunidades religiosas es el abandono, nos preguntamos cómo pueden surgir otros caminos de respuesta a las situaciones decepcionantes que surgen en el seno de las organizaciones carismáticas.

Albert Hirschman (1977) plantea dos caminos utilizados por los miembros de las instituciones como respuesta al deterioro organizacional, se trata de dos fuerzas endógenas de recuperación: la salida y la voz. En su estudio el autor supone el deterioro de una organización por variedad de causas, que no son tan fuertes para impedir la reparación, y siempre que los responsables sepan dirigir su atención y su energía a la necesidad de remediar la situación.

Buscaremos articular sus aportes como una contribución a un ejercicio de discernimiento evangélico, que nos permita presentar caminos alternativos frente a los abandonos en las realidades carismáticas de la Iglesia. Si bien el autor analiza estas dos opciones primordialmente desde perspectivas económicas, y en un segundo momento desde enfoques políticos, consideramos enriquecedor para nuestro tema hacer una lectura -como también lo hace Bruni- desde el punto de vista de las organizaciones motivadas por ideales o realidades carismáticas, como las congregaciones religiosas, nuevos movimientos eclesiales o nuevas formas de vida consagrada. 
El deterioro de la organización queda en evidencia por dos caminos: algunos miembros abandonan el organismo y en consecuencia el número disminuye [opción de la salida]; otros miembros expresan la insatisfacción a sus superiores o comienzan a protestar frente a quien quiera escucharlos [opción de la voz].

Por ello es interesante extrapolar el análisis comparativo, realizado por Albert Hirschman, de las opciones de la salida y de la voz y su interconexión a este tipo de organizaciones. Así podemos traducir las preguntas del autor del siguiente modo: ¿En qué condiciones prevalecerá en una organización carismática la opción de la salida sobre la de la voz y viceversa? ¿Cuál es la eficacia comparativa de estas opciones como mecanismos remediales en las organizaciones motivadas por ideales? ¿En qué circunstancias se suceden ambas opciones? ¿Qué mecanismos podrían implementarse para lograr que estas opciones sean formas de reparar las fallas de las organizaciones? (Hirschman, 1977, p. 14)

En primer lugar, la voz es -en las organizaciones- el recurso de la palabra y del discurso por parte de los miembros comprometidos, y puede graduarse desde el débil murmullo hasta la protesta violenta; implica la articulación de las opiniones críticas en un mensaje directo y claro antes que estrategias que dilaten y retrasen la comunicación del conflicto; se trata de una acción política por excelencia que busca el cambio frente al deterioro de la organización (Hirschman, 1977, p. 24).

En segundo lugar, la salida es el recurso de quien no encuentra caminos adecuados para lograr un cambio en la situación actual que se vivencia con una alta carga de frustración y negatividad. Este recurso de protesta frente al deterioro de la organización es tildado de ineficaz, oscuro y criminal al presentarlo como deserción, defección y traición (Hirschman, 1977, p. 25). Esta visión queda de manifiesto en la utilización del término "defección» para referirse a la salida de la vida religiosa, dado que el término supone la acción desleal de separarse de la organización o causa de pertenencia.

En general, la opción de la salida, es percibida por los miembros de una organización sostenida desde un alto ideal como un abandono que implica la falta de lealtad del miembro que se distancia sobre el conjunto o sobre el proyecto carismático que se llevaba adelante.

Debido a ello, los miembros insatisfechos de un organismo emplean la voz, en lugar de la salida, en un intento por cambiar las prácticas del organismo al que pertenecen:

Definimos aquí la voz como un intento por cambiar un estado de cosas poco satisfactorio, en lugar de abandonarlo, mediante la petición individual o colectiva a los administradores directamente responsables, mediante la apelación a una autoridad superior con la intención de forzar un cambio de administración, o mediante diversos tipos de acciones y protestas, incluyendo las que tratan de movilizar la opinión pública (Hirschman, 1977, p. 16).

Frente a la declinación de un organismo, los miembros descontentos pueden elegir entre las opciones de la voz y la salida. Si las condiciones son tales que la declinación conduce a la voz antes que a la salida aumentará la eficacia de la voz y su volumen. Pero la voz se asemeja a la salida por cuanto puede llegar a ser exagerada, los miembros descontentos pueden volverse tan amenazadores que sus protestas perjudicarían en algún momento, en lugar de ayudar a los esfuerzos de recuperación que se inicien: "La voz tiene la función 
de alertar a una empresa u organismo acerca de sus fallas, pero luego debe dar a la administración, vieja o nueva, cierto tiempo para responder a las presiones que le hayan impuesto" (Hirschman, 1977, p. 38).

La opción de la voz es la elección de los miembros insatisfechos, quienes no están dispuestos a dejar la organización. Estos serán quienes ante la baja de calidad de la experiencia vivida son capaces de articular un discurso que exprese su descontento, frustración o decepción.

\section{La lealtad en las organizaciones carismáticas}

Albert Hirscham desarrolla una teoría de la lealtad, como apego especial de los miembros a una institución, para analizar cómo afecta la presencia de la opción de la voz o de la salida en las organizaciones (Hirschman, 1977, pp. 78-104).

La elección de la salida elimina la posibilidad de articular un discurso que exprese la insatisfacción; por ello, la voz desempeña un papel importante en las organizaciones en las que la lealtad genera produce que la opción de la salida sea más difícil, o normalmente impensable, aunque no imposible.

En presencia de la lealtad los miembros de una comunidad se inclinan por el recurso de la voz por dos razones: consideran más valiosa la posibilidad de un mejoramiento incierto que las certezas que pueda proveer la salida de la institución; estiman que tienen posibilidades y capacidades para influir positivamente para remediar el deterioro de la organización. Por ello "la probabilidad de la voz aumenta con el grado de lealtad" (Hirschman, 1977, p. 79).

Los miembros leales, que se consideran capaces de influir en el cambio institucional, buscarán ganar influencia para contribuir a revertir el deterioro y tenderán a identificarse afectivamente con la organización que cuenta con el poder de hacer algo:

Así pues, por regla general la lealtad aleja la salida y activa la voz. Es cierto que, frente al descontento con la forma como marchan las cosas en un organismo, un miembro individual puede permanecer leal sin ser él mismo influyente, pero difícilmente sin la esperanza de que alguien actuará o algo sucederá que mejore las cosas (Hirschman, 1977, p. 80).

La lealtad, como valor de una organización motivada por ideales, neutraliza la tendencia de los miembros más preocupados por el deterioro a ser los primeros en salir. Esto es muy importante, pues previene la salida de los integrantes con más posibilidad de contribuir positivamente a un cambio y alimenta la expectativa razonada de que la reforma se logre desde dentro:

La lealtad actúa ahora como freno a la decisión de abandonar. El miembro leal no abandona, pero algo le ocurre: empieza a sentirse muy infeliz por continuar como miembro, le viene náuseas o Bauchschmersen (dolores de estómago) [...]. Normalmente hará mayores esfuerzos que hasta ahora por cambiar la línea e intensificará el empleo de la voz en sus diversas formas para este fin... (Hirschman, 1977, p. 88). 
La barrera informal y generalizada de la lealtad empuja a la desidentificación de la salida, con la consecuente búsqueda de nuevas formas de presión e influencia en pro de la recuperación de la institución, e impulsa una mayor determinación e ingenio en el empleo de la voz.

Al ser la voz la respuesta usual de disconformidad con la marcha de la organización, uno de los modos de potenciarla es la «amenaza de la salida" que "será hecha típicamente por los leales, es decir, por los miembros que se preocupan, quienes no dejarán piedra sin mover antes de resignarse a la decisión dolorosa de retirarse" (Hirschman, 1977, p. 84).

Otro modo de potenciar la voz será el «boicoteo» o la «no colaboración» que se ubican en un punto medio entre la voz y la salida; sin ser una salida definitiva, los miembros descontentos ven necesario potenciar el recurso de la voz, y por ello retiran sus energías de algunas tareas para dar fuerza al discurso expresado.

\section{7. «Sin salidas»: cuando fomentar la lealtad supone reprimir la voz y la salida}

Cuando la salida de algún modo es una «elección complicada», como en las realidades carismáticas, un modo de acción posible para las autoridades de la institución es restringir el recurso a la voz en los miembros insatisfechos (Hirschman, 1977, p. 78). La centralización verticalista en el ejercicio de la autoridad, la escasa colegialidad, la ausencia de oportunas delegaciones, la concentración del gobierno en manos de uno, la falta de escucha a los Consejos o decisiones capitulares, el recurso a mayorías pre-constituidas o la «lógica de las coaliciones», todos ellos son ejemplos de mecanismos erróneos que restringen el recurso a la voz en las instituciones carismáticas (CIVCSVA, 2017, pp. 19-21).

Cuando el recurso a la voz es inhabilitado queda a los miembros insatisfechos la salida como expresión de su decepción: "Ante cualquier solicitud de abandono habría que preguntarse seriamente sobre las responsabilidades del conjunto de la comunidad y, en particular, de los superiores" (CIVCSVA, 2017, p. 21).

El comportamiento leal que recurre creativamente a la voz por sobre la salida, puede verse modificado cuando en las organizaciones motivadas por ideales se busca reprimir la salida y la voz conjuntamente. En el corto plazo a las autoridades les beneficia la ausencia de cualquier comportamiento disonante, permitiéndoles sostener el statu-quo y el control de las decisiones de la organización: "Se observa el fenómeno de superiores a quienes solo les preocupa mantener el Statu quo, aquel «siempre se ha hecho así» (CIVCSVA, 2017, p. 19).

Dos factores afectan el comportamiento leal que busca privilegiar el discurso transformador sobre la salida: la iniciación severa y los castigos graves por la salida: "Los honorarios elevados para ingresar a un organismo y las penas severas por la salida son algunos de los instrumentos principales generadores o reforzadores de la lealtad que finalmente reprimen la salida, la voz, o ambas cosas” (Hirschman, 1977, p. 93).

Cuando más costoso o trabajoso, en términos de costos subjetivos para la incorporación como miembro pleno, sea el ingreso de un miembro en una organización carismática -o requiere de una iniciación severalas personas tenderán más a demorar el reconocimiento de todo deterioro institucional o retrasarán iniciar 
sus quejas y protestas. Cuando la posibilidad de la salida se encuentra marcada, imaginaria o realmente, de múltiples dificultades y carencias será también un impedimento para que las personas expresen, con relativa autonomía, las dificultades que experimentan para vivir desde motivaciones profundas el proyecto carismático en que se han comprometido.

Este tipo de modificación del comportamiento leal puede verse reflejado en la denuncia de hechos de manipulación de la libertad y de la dignidad de las personas, o en las reflexiones sobre el concepto de obediencia en la vida religiosa y en las nuevas comunidades. Modos erróneos de concebir la obediencia conllevan peligros reales, peligrosos, y pueden convertirse en la ocasión de desviaciones y perversiones que, lejos de liberar a las personas, las alienan y las hieren profundamente (Donneaud, 2017, p. 39).

Otras maneras de producir estructuras que estorban un comportamiento leal que busca la transformación es fomentar un acompañamiento espiritual creador de dependencias, en el que las modalidades de acompañamiento impiden la autonomía personal y producen conductas que buscan ser protegidos dentro un esquema de control infantil (Francisco, 2017).

\section{8. «Otras salidas». Ensayando una conclusión para estas reflexiones}

[...] sucede a las mejores OMI, que se asemejan mucho a los artistas, a las personas geniales - no hay en el mundo realidades más creativas, sublimes, apasionantes que las OMI. El oficio más importante de sus fundadores y/o responsables es lograr ver dentro de la marea del éxito sus potenciales autodestructivos y comportarse en consecuencia, poniendo en obras elecciones organizativas drásticas y dolorosas (por ejemplo, desalentado las homologaciones de sus miembros, reduciendo las distancias entre los líderes y el grupo, combatiendo la autorreferencialidad, no complacerse en escuchar en sus propios seguidores un eco de su voz, favoreciendo la autonomía de pensamiento de las personas (Bruni, 2017, p. 66).

Luego de haber señalado las dificultades que pueden encontrar los miembros descontentos de una organización motivada por ideales ensayamos algunas conclusiones abriendo un horizonte de esperanza. Como señala Hirschman, en las organizaciones siempre existen recursos y capacidades ocultos o mal utilizados, se trata de un cierto «margen» que actúa como una reserva y puede aprovecharse y activarse frente a la declinación y el peligro (Hirschman, 1977, pp. 21-23).

Este margen para reaccionar positivamente en la vida práctica y concreta de las organizaciones es capaz de ser movilizado por las acciones de los miembros descontentos que ponen en juego los mecanismos de la voz, la salida y la no cooperación con el orden establecido y con las dinámicas de continuidad sin reforma.

Para esto será necesario profundizar en el desarrollo de la autonomía de las personas y "garantizar la transmisión equilibrada, prudente y clara de lo que sigue siendo el tesoro de todo radicalismo evangélico, el compromiso de obediencia para desplegar mejor la auténtica libertad de los hijos de Dios en Cristo" (Donneaud, 2017, p. 53). 
Frente a los nudos complejos y paralizantes de las instituciones y el cansancio de sus miembros se abren los caminos de la escucha a las voces disonantes de los miembros descontentos y a los discernimientos de la autoridad eclesial; se extiende también la posibilidad de contrastar estas visiones con la antigua experiencia de la comunidad eclesial y con las causas profundas de las escandalosas crisis de algunas organizaciones carismáticas en las últimas dos décadas.

Surge frente a estas dificultades la inquietud de iniciar procesos de actualización impulsados por la riqueza inextinguible del Espíritu Santo que, con su presencia renovadora, garantiza la continuidad de la acción evangelizadora de la Iglesia, por medio de sus dones jerárquicos y carismáticos.

Las nuevas organizaciones carismáticas ofrecen a la comunidad eclesial modos posibles de vivir la fe en un contexto de fuerte secularización y globalización y es de desear que estos aportes de renovación encuentren cauces que les permitan una evolución sana y fructífera.

\section{Referencias}

Abignente, L. (2018). Doni gerarchici e carismatici: Il primato della comunione nel cammino storico-spirituale del Movimento dei Focolari alla luce della Lettera Iuvenescit Ecclesia. Roczniki Teologiczne, 65(5), 107-120. Recuperado a partir de https://doi.org/10.18290/rt.2018.65.5-8

Areitio, M. (2010). Asociaciones de fieles y vida consagrada: distintas relaciones y sus perspectivas canónicas. Ius Canonicum, 50(99), 129-161. Recuperado a partir de https://revistas.unav.edu/index.php/ius-canonicum/ article/view/2655/2527

Bahíllo Ruiz, T. (2016). Significado de las sociedades de vida apostólica en la Iglesia Vicencianismo y vida consagrada (pp. 111-142). Salamanca: Ceme. Recuperado a partir de http://hdl.handle.net/11531/17396

Bamberg, A. (2009). Protección de los votos y nuevas realidades eclesiales. Ius Canonicum, 49(98), 603-614. Recuperado a partir de https://revistas.unav.edu/index.php/ius-canonicum/article/view/2686/2557

Beltramo Álvarez, A. (2014). La Santa Sede reconoce: existen «otros» Maciel, 31 de enero de 2014. La Stampa.

Bruni, L. (2017). La destrucción creadora. Cómo afrontar las crisis en las organizaciones motivadas por ideales. Buenos Aires Ciudad Nueva.

Bruni, L., \& Smerilli, A. (2009). The Value of Vocation. The Crucial Role of Intrinsically Motivated People in Values-based Organizations. Review of Social Economy, 67(3), 271-288. Recuperado a partir de https://doi. org/10.1080/00346760802621633

Bunton, P. (2019). Reflexivity in practical theology: reflections from studies of founders' succession in Christian organizations. Practical Theology, 12(1), 81-96. Recuperado a partir de https://doi.org/10.1080/175607 3X.2019.1575039

Cattaneo, A. (1998). Los movimientos eclesiales. Cuestiones eclesiológicas y canónicas. Ius Canonicum, 38(76), 571594. Recuperado a partir de https://revistas.unav.edu/index.php/ius-canonicum/article/view/15895/11891

Coda, P. (2018). Nuovi movimenti ecclesiali: aspetti teologici ed ecclesiologici. Giornata di Studio «Carisma e Istituzione in Movimenti e Comunità ecclesiali», 18 de enero de 2018. Roma. 
Codina, V. (1994). Eclesialidad de la vida religiosa Theologica Xaveriana, 110, 159-182. Recuperado a partir de https://revistas.javeriana.edu.co/index.php/teoxaveriana/article/view/21455

Congregación para la Doctrina de la Fe. (2016). Carta Iuvenescit Ecclesia a los Obispos de la Iglesia Católica sobre la relación entre los dones jerárquicos y carismáticos para la vida y misión de la Iglesia. Vaticano: Librería Editrice Vaticana. Recuperado a partir de https://goo.gl/rYvukc.

Congregación para los Institutos de Vida Consagrada y las Sociedades de Vida Apostólica - CIVCSVA. (2017). A vino nuevo, odres nuevos. La vida consagrada desde el Concilio Vaticano II: retos aún abiertos. Buenos Aires: Claretianas.

Conner, P. M. (1999). Vita consecrata: an Ultimate Theology of the Consecrated Life. Angelicum, 76(2), 245-273. Recuperado a partir de https://www.jstor.org/stable/44617185

Delgado Galindo, M. (2010). Asociaciones internacionales de fieles. Ius Canonicum, 50(99), 9-29. Recuperado a partir de https://revistas.unav.edu/index.php/ius-canonicum/article/view/2652/2524

Delgado Galindo, M. (2013). La primavera de la Iglesia. Movimientos eclesiales, fieles laicos y nueva evangelización. Buenos Aires: De la Palabra de Dios.

Donneaud, H. (2017). Liberté et obéissance dans les Communautés nouvelles. Communio, 42, 39-52.

Duhau, J. B. (2019). Carisma e institución en las nuevas realidades carismáticas. Crecimiento y crisis en los movimientos eclesiales y nuevas comunidades. Teología, 55(127), 189-212. Recuperado a partir de http:// erevistas.uca.edu.ar/index.php/TEO/article/view/1673

Eisenstadt, S. N. (1973). El carisma, la creación de instituciones y la transformación social. Revista de estudios políticos, 187, 65-112.

Etxeberría, J. J. (2019). Los Movimientos Eclesiales: Fenomenología y Cuestiones Abiertas. Estudios Eclesiásticos, 76(296), 5-33. Recuperado a partir de https://revistas.comillas.edu/index.php/estudioseclesiasticos/article/ view/11160

Faggioli, M. (2019). The Catholic Sexual Abuse Crisis as a Theological Crisis: Emerging Issues. Theological Studies, 80, 572-589. Recuperado a partir de https://doi.org/10.1177/0040563919856610

Faggioli, M., \& Yocum, D. S. (2014). Sorting Out Catholicism: A Brief History of the New Ecclesial Movements: Liturgical Press. Recuperado a partir de https://muse.jhu.edu/book/46640

Francisco. (2017). Discurso a los participantes en la plenaria de la CIVCSVA, 28 de enero de 2017. Recuperado a partir de https://goo.gl/AtRXGt

Fuenmayor, A. (1983). La erección del Opus Dei en Prelatura Personal. Ius Canonicum, 23(45), 9-58. Recuperado a partir de https://revistas.unav.edu/index.php/ius-canonicum/article/view/19185/15716

Fuenmayor, A., \& Rodríguez García, P. (1984). Sobre la naturaleza de las Prelaturas personales y su inserción dentro de la estructura de la Iglesia. Ius Canonicum, 24(47), 11-50. Recuperado a partir de https://revistas.unav.edu/ index.php/ius-canonicum/article/view/19167/15576

Gerosa, L. (1988). Carismi e movimenti nella Chiesa oggi. Reflessioni canonistiche alla chiusura del Sinodo dei Vescovi sui laici. Ius Canonicum, 28(56), 665-680. Recuperado a partir de https://dadun.unav.edu/ handle/10171/16478

González Ayesta, J. (2009). Líneas maestras de la normativa del CIC 83 sobre la vida consagrada y algunas cuestiones actuales en esta materia. Ius Canonicum, 49(97), 101-123. Recuperado a partir de https://doi. org/10.15581/016.97.\%25p 
Hirschman, A. O. (1977). Salida, voz y lealtad. México: Fondo de Cultura Económica.

Hortal, J. (1971). Estado de vida consagrada - estado secular. Perspectiva Teológica, 3(5), 197-212. Recuperado a partir de http://www.faje.edu.br/periodicos/index.php/perspectiva/article/view/2522/2732

Howard, E. B. (2019). The Beguine Option: A Persistent Past and a Promising Future of Christian Monasticism. Religions, 10(491). Recuperado a partir de https://doi.org/10.3390/rel10090491

Keenan; W. J. F (2002) Twenty-First-Century Monasticism and Religious Life: Just Another New Millennium, Religion, 32(1), 13-26, https://doi.org/10.1006/reli.2002.0395

Ker, I. (2002). New Movements and Communities in the Life of the Church. Louvain Studies, 27(1), 69-95. Recuperado a partir de https://doi.org/10.2143/LS.27.1.928

Ker, I. (2005). The priesthood and the new ecclesial movements and communities. Louvain Studies, 30(1-2), 124136. Recuperado a partir de https://doi.org/10.2143/LS.30.1.583240

Leidi, L. (2014). Nuevos carismas: dimensión histórico-jurídica. Unidad y carismas 90 (2014) 13-18.

Leonard, E. M. (2001). Ecclesial Religious Communities Old and New Way Supplement, 101, 119-128. Recuperado a partir de https://www.theway.org.uk/back/s101Leonard.pdf

Madrigal Terrazas, S. (2006). El concilio de la Iglesia sobre la Iglesia. Estudios Eclesiásticos, 81, 297-331. Recuperado a partir de https://revistas.comillas.edu/index.php/estudioseclesiasticos/article/view/9537

Madrigal Terrazas, S. (2015). El liderazgo carismático de Suenens y Lercaro en el Vaticano II. Estudios Eclesiásticos, 352, 3-39. Recuperado a partir de https://revistas.comillas.edu/index.php/estudioseclesiasticos/article/view/7082

Martinelli, P. (2017). Natura della coessenzialità tra doni gerarchici e carismatici nella Chiesa. Una lettura della Lettera "Iuvenescit Ecclesia" (2016). Revista española de Teología, 77(1-2), 105-133.

Matas Pastor, J. J. (2000). Origen y desarrollo de los Cursillos de Cristiandad (1949-1975). Hispania sacra 52 (106) 719-741. Recuperado a partir de https://doi.org/10.3989/hs.2000.v52.i106.579

Meis-Wörmer, A. (2009). El Espíritu Santo y la comunidad cristiana en el Documento Conclusivo de Aparecida. Veritas, 4(21), 343-364. Recuperado a partir de https://drive.google.com/file/ d/0B4grM4LYlzhWT3I2UG9iVVR3dDQ/edit

Miras, J. (1999). Tradición canónica y novedad en el concepto de prelatura. Ius Canonicum, 39(78), 575-604. Recuperado a partir de https://doi.org/10.15581/016.78.575-604

Navarro, L. (2008). La incardinacion de los clérigos de los movimientos eclesiales. Ius Canonicum, 48(95), $247-$ 276. Recuperado a partir de https://revistas.unav.edu/index.php/ius-canonicum/article/view/14183/15100

Navarro, L. (2018). Nuevos movimientos eclesiales. Naturaleza de los carismas, cuestiones jurídicas y límites. Ius Canonicum, 58(116), 611-634. Recuperado a partir de https://doi.org/10.15581/016.116.005

Otaduy Guerín, J. (2018). Unidad y pluralidad en la Iglesia. El pluralismo carismático. Ius Canonicum, 58(116), 635-670. Recuperado a partir de https://doi.org/10.15581/016.116.003

Oviedo Cavada, C. (1984). Carisma e institucionalidad en la Iglesia. Teología y vida, 25(4), 309-323. Recuperado a partir de https://repositorio.uc.cl/handle/11534/15169

Polanco, R. (2003a). La Iglesia como espacio sagrado de encuentro. Teología y vida, 44, 332-345. Recuperado a partir de http://dx.doi.org/10.4067/S0049-34492003000200014 
Polanco, R. (2003b). La Iglesia y la universalidad de la salvación en el cristianismo. Teología y vida, 44, 423-443. Recuperado a partir de http://dx.doi.org/10.4067/S0049-34492003000400005

Rambaldi, G. (1975). Uso e significato di 'Carisma' nel Vaticano II: Analisi e confronto di due passi conciliari sui carismi. Gregorianum, 56(1), 141-162. Recuperado a partir de https://www.jstor.org/stable/23575314

Rambaldi, G. (1987). Carismi e laicato nella Chiesa: Teologia dei carismi, comunione e corresponsabilità dei laici nella Chiesa. Gregorianum, 68(1/2). Recuperado a partir de https://www.jstor.org/stable/23577661

Ratzinger, J. (1999). Los movimientos eclesiales y su lugar teológico. Communio, 20, 87-108.

Rodríguez García, P. (1970). Ministerio y comunidad. Estudio de sus relaciones en orden a la fundamentación de una teología del ministerio eclesiástico. Scripta Theologica, 2(1), 119-142. Recuperado a partir de https:// doi.org/10.15581/006.2.1.119-142

Santos Díez, J. L. (1967). Jerarquía y carisma en el gobierno de la Iglesia. Ius Canonicum, 7(14), 321-363. Recuperado a partir de https://revistas.unav.edu/index.php/ius-canonicum/article/view/22279/18509

Schilier, H. (1979). El Espíritu Santo en el Nuevo Testamento. Scripta Theologica, 11(3), 1005-1019. Recuperado a partir de https://doi.org/10.15581/006.11.3.1005-1019

Schoon, E. W., \& West, A. J. (2017). From Prophecy to Practice: Mutual Selection Cycles in the Routinization of Charismatic Authority. Journal for the Scientific Study of Religion, 56(4), 781-797. Recuperado a partir de https://doi.org/10.1111/jssr.12483

Theobald, C. (2016). El fundamento común en la diversidad de las formas. Proceso en acción. Vida Religiosa, 120, $135-166$.

Viana, A. (1997). La prelatura personal en la estructura constitucional de la Iglesia. Observaciones sobre un libro reciente. Ius Canonicum, 37(74), 749-763. Recuperado a partir de https://revistas.unav.edu/index.php/iuscanonicum/article/view/15929/11271

Viana, A. (2008). Pasado y futuro de las Prelaturas Personales. Ius Canonicum, 48(95), 141-182. Recuperado a partir de https://revistas.unav.edu/index.php/ius-canonicum/article/view/14186/15096

Viana, A. (2012). Ordinariatos y prelaturas personales. Aspectos de un diálogo doctrinal. Ius Canonicum, 52(104), 481-520. Recuperado a partir de https://revistas.unav.edu/index.php/ius-canonicum/article/view/450/250

Vigano, E. (1985). Teología y vida religiosa después del Concilio Vaticano II. Teología y vida, 6(4), 255-272.

Villar, J. R. (1998). El Espíritu Santo, «Principium unitatis Ecclesiae». Scripta Theologica, 30(3), 831-860. Recuperado a partir de https://hdl.handle.net/10171/13336

Zollner, H. (2018). Las heridas espirituales causadas por los abusos sexuales. La Civilltà Cattolica Iberoamérica, 12, 51-61. 